\title{
Ethnomedicines used by Kaani Tribes in the Forest and Towns of Kanyakumari District in Tamilnadu
}

\section{Mohankumar $\mathrm{JB}^{* 1}$, and Velvizhi $\mathrm{M}^{2}$}

${ }^{1}$ Emeritus Professor, Department of Nutrition and Dietetics, PSG College of Arts and Science, Coimbatore-14, India ${ }^{2}$ Ph.D. Research Scholar, Department of Nutrition and Dietetics, PSG College of Arts and Science, Coimbatore-14, India

${ }^{*}$ Corresponding author: Mohankumar JB, Emeritus Professor, Department of Nutrition and Dietetics, PSG College of Arts and Science, Coimbatore-14, India, Tel: 9443754589, E-mail: mohanjemi1502@yahoo.com

Citation: Mohankumar JB, Velvizhi M (2018) Ethnomedicines used by Kaani Tribes in the Forest and Towns of Kanyakumari District in Tamilnadu. J Nutr Health Sci 5(2): 205. doi: 10.15744/2393-9060.5.205

Received Date: March 05, 2018 Accepted Date: May 17, 2018 Published Date: May 24, 2018

\begin{abstract}
Kaani Tribes have traditionally depended on harvests of forest, wildlife, and forest products. The main objective of this study was to see if the Kaani tribes have lost the knowledge and use of herbs in treating diseases while relocating to city life. Ethnomedicinal data was collected through Participatory Town Appraisal (PRA), which is based on interaction with indigenous people and direct observation in the field and interviews and discussions with Mootukani, the medicine man for the tribals. Authenticated information was also collected from the elder people (women and men) through effective survey. Informations regarding plants, parts used, usage, mode of preparation and doses were documented. Information gathered was cross checked between people in the subsequent visits. The data was recorded through semi-structured interviews with Kaani villagers in the forest and also those in the tribal community who had moved to the neighbouring towns. A total of 500 people were interviewed. Ethnomedicine data was analysed using informant consensus factor and use value. We found that the knowledge and use of ethnomedicines is lower among the Kaani tribes who have moved out of the forest. We suggest that it is urgent to transform knowledge and practice of traditional ethno medicine into research and scientific based medicinal products that are well documented and available in the public domain.
\end{abstract}

Keywords: Kaani Tribes; Informant consensus factor; Use value; Ethno medicinal plants

\section{Introduction}

The traditional livelihood system of tribal people (also known as adivasis) is based on cultivation and collection of edible forest produce. Kaanikkars are also known as Kaanikkaran or Kaani. The general name for these tribes in Kanyakumari area is 'Kaani'. The word Kanikar means hereditary proprietor of land. The term 'Kaan' meaning 'Kaatu' (forest) becomes the root of the word 'Kaanikkars, Kaanikkaran or Kaani'. So, this shows that Kaani are people who live in forest. This evolved to get the term Kaani. A Kani tribe settlement is typically a cluster of few families living interspersed with the forest, isolated from any public transports facility. They speak Malayalam mixed Tamil. The Kani tribes live in harmony with nature and the eco-system. They live in bamboo nets, mainly derive their food from forest produce and still maintain the hunter-gather instincts. They have their own special life styles, culture, customs, traditions and religious practices. A smaller portion of their population has now settled in permanent villages as well as in towns and cities. There appears to be a decline in the collection and use of traditional foods raising question about nutrition and health security among tribes [1].

Historically the tribal community's survive on their traditional knowledge. Maintenance of their health is based on the medicine plants [2]. The most common reasons for using traditional medicine are that it is more affordable, more closely corresponds to the patient's ideology, allays concerns about the adverse effects of chemical (synthetic) medicines, satisfies a desire for more personalized health care, and allows greater public access to health information. The major use of herbal medicines is for health promotion and therapy for chronic, as opposed to life-threatening, conditions. However, usage of traditional remedies increases when conventional medicine is ineffective in the treatment of disease, such as in advanced cancer and in the face of new infectious diseases.

The use of plants as medicines has a long history in the treatment of various diseases. The plant-derived compounds have a long history of clinical use, better patient tolerance and acceptance. To date, 35,000-70,000 plant species have been screened for their medicinal use. Plants especially those with ethno-pharmacological uses have been the primary sources of medicine for early drug 
discovery. $25 \%$ of modern medicines are made from plants first used traditionally [3].

Qualitative compilation style of the knowledge of ethno medicinal plants does not have much scope for making objective comparisons. They examined the relative importance of plant for different groups of tribal people. But these studies did not approach the variation on the ethno botanical knowledge of informants. By incorporating suitable quantitative methods in collection, processing and interpretation of data on ethno-medicines permit the testing of hypothesis statistically. Because the variables are quantitatively expressed, it increases the indicative value of studies on ethno-medicinal plants.

Some of the Kaani tribes have moved out of the forest area to the nearby town areas due to the dwindling forest resources. While looking for economic sustainability, they have had to bring in changes in their lifestyle in keeping with the town environment. Traditional medicinal plants as herbal remedies have been used by tribal people all over the world for centuries. Kaanis also have a history of traditional medicine, which is passed on from generation to the next by a hierarchy of traditional healers called the "Plathi and Mootukani". However, this system of medicine does fade away when the environment in which the Kaanis live changes [4].

Hence the objective of our study was to quantitatively ascertain the changes in knowledge and application of ethno medicinal plants among the Kaani tribes of Kanyakumari district in Tamil Nadu. We identified this area because studies of this type have not been carried out in this environment. Quantitative ethno medicine research has been carried out wherever tribes and aboriginals continue to live in their native environment. Our focus was on how the knowledge and use of is being forgotten due to lifestyle changes. Hence we have set a null hypothesis that the use value and the informant consensus factor of medicinal plants among Kaani tribes in the forest area and town area are similar.

\section{Methodology}

\section{Study Area}

The study areas selected was Kanyakumari district of Tamil Nadu. Kanyakumari district is situated in the southernmost part of Western Ghats region which is located between $77^{\circ} 15^{\prime}$ and $77^{\circ} 36^{\prime}$ of east of longitude and $8^{\circ} 03^{\prime}$ and $8^{\circ} 35^{\prime}$ north of Latitude.

The indigenous people of the study area are Kaani who live predominantly in and around Kanyakumari district of TamilNadu. This specific area was selected for the study as we found that Kaani people in Tirunelveli [5] and Kerala [6-7] have been studied by other researchers. The study was conducted in the villages of Mothiramalai, Thottamalai, Chappangupparai, Koovaikadu, Kothaiyar, Alamparai, Koruvakuzhi, Kothaiyar, Koovaikadu, Puravilai, Valayamthanki, Thottamalai, Chappangupparai, Vannachipparai, Mothiramalai, Thottamalai, Chappangupparai, Koovaikadu of Thiruvattar and Thovallai of Kanyakumari District. Pechiparai hills, Perunchani hills, Arrukaani hills, Kothaiyaru, Keeriparai and Pathukaani hills are the forest area where there are about $50-100$ Kaani families in each of the locations.

\section{Study Area Map}

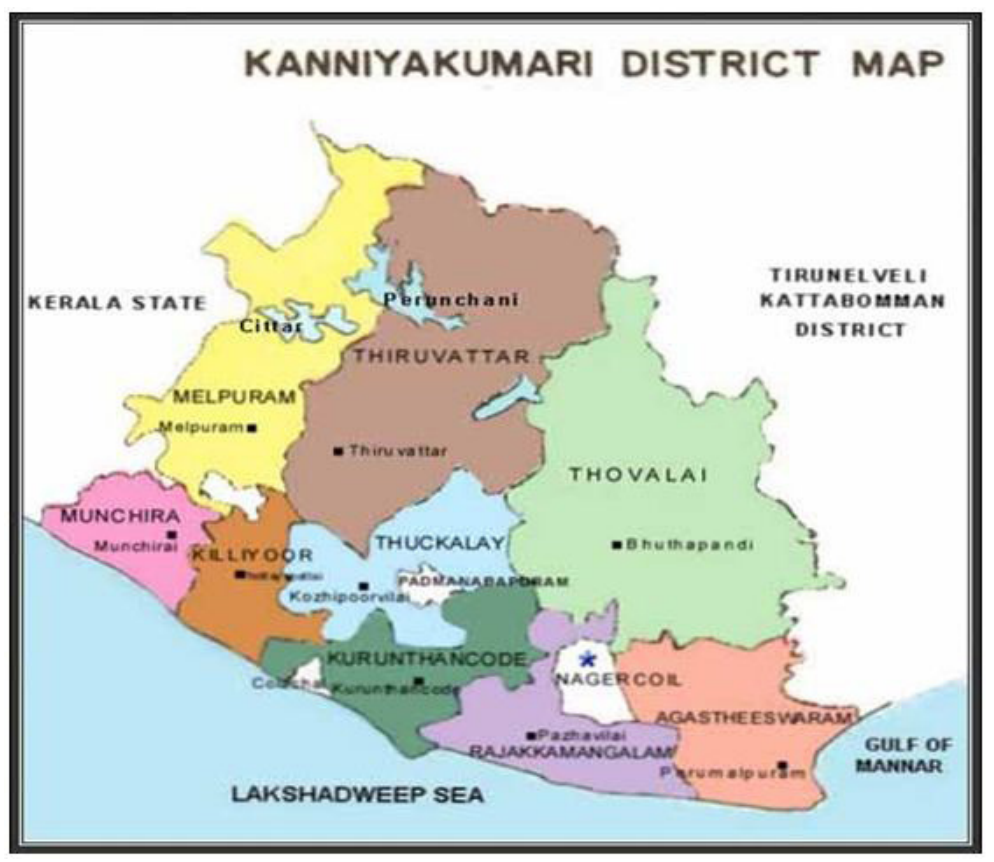

Figure 1: Ethical clearance

We followed the guidelines of ICMR (2006) [9] to protect and respect rights and welfare of human subjects as participants in research [4]. We provided the respondents with the informed consent document and explained its content. We got the approval from the PSG College of Arts \& Science, Research Ethical Committee on 14.03.2015. REC/NCND/K15003. 
Sample size was determined on the current Census (2011) and projection for 2015 [10] Kaani population in Kanyakumari district, using the online calculator website at https://www.surveysystem.com/sample-size-formula.htm [11]. The survey included 360 adult men and women from the forest and surrounding towns. The respondents were identified through the snowball technique. The details of the respondents are given in the following Table 1. The survey was conducted between May 2015 and June 2016.

\begin{tabular}{|c|c|c|c|c|c|c|c|}
\hline \multirow{2}{*}{ S.No } & \multirow{2}{*}{$\begin{array}{c}\text { Age } \\
\text { group }\end{array}$} & \multicolumn{3}{|c|}{ Forest area $(\mathbf{n = 1 8 0})$} & \multicolumn{3}{c|}{ Town area $(\mathbf{n = 1 8 0})$} \\
\cline { 3 - 8 } & Male & Female & Percent & Male & Female & Percent \\
\hline 1. & $25-35$ & 35 & 28 & 35.0 & 51 & $\mathbf{3 4}$ & 47.2 \\
\hline 2. & $35-45$ & 67 & 40 & 59.4 & 41 & $\mathbf{5 3}$ & 52.2 \\
\hline 3. & $45-55$ & 4 & 6 & 5.6 & 1 & $\mathbf{0}$ & 0.6 \\
\hline \multicolumn{7}{|c|}{$38.3 \pm 5.3$} \\
\hline
\end{tabular}

Ethno medicinal data was collected through Participatory Rural Appraisal (PRA) [12], which is based on interaction with indigenous people and direct observation in the field and interviews and discussions with Mootukani, the traditional healer for the Kaanis. Twenty commonly used ethno medicinal plants belonging to 13 different botanical families were selected for our study. Traditional knowledge of ethno medicinal plants was gathered mainly through individual interviews with selected informants using an Ethno-Medico-Botanical Datasheet13. Interviews were conducted in local language with the help of a local leader and responses were recorded in English. During the interview with each informant, information regarding the type of ailments managed by the ethnic group against the reported ailments, the plant parts used, ways of remedy preparations, route of administration, precautions if any and dosage was gathered. The information was also discussed with five healers in the localities to validate the claims as far as possible.

Database on medicinal plants given by the Encyclopaedia of Medicinal Plants (https://herbs.indianmedicinalplants.info/) [14] was used for the identification of the plants collected from the study area. Digital record of the collected plants was maintained and the local name was obtained from the tribes to enable accurate identification. A botanist was also consulted to make sure that the name of the plant in the local language (Tamil) and its botanical name was correct.

Information gathered was cross checked between people in the subsequent visits. The data was recorded through semi-structured interviews with Kaani villagers in the forest and those in the tribal community who had moved to the neighbouring villages. During the field survey, information on uses of plants to treat different illnesses of human being, parts used, modes of preparation and administration of medicine were collected. Ethno medicine data was analysed using informant consensus factor and use value.

Herbs are valued for their virtues as food as well as medicine. Herbal remedies may be prepared in different ways for use in treatment of diseases and ailments as decoctions, infusions, concoctions, maceration and bathing remedies. Ethno botanical studies are important in revealing locally important plant species. Documentation of indigenous knowledge of medicinal plants is important for preserving the traditional medicines before it vanishes with the changes in lifestyle of tribal people. In this way ethno medicinal plants can be conserved and scientifically studied for drug discoveries.

Informant consensus factor (FIC): The informant consensus factor (FIC) was used to see if there was agreement in the use of plants in the ailment categories between the plant users in the study area. FIC Values range between 0 and 1, where ' 1 ' indicates the highest level of informant consent. The level of homogeneity among information provided by different informants was calculated by the Informants' Consensus Factor, FIC using the following formula [15].

$$
\mathrm{Fic}=\frac{\mathrm{Nur}-\mathrm{Nt}}{\text { Nur-1 }}
$$

Where Nur refers to the number of use-reports for a particular ailment category and Nt refers to the number of taxa used for a particular ailment category by all informants. The product of this factor ranges from 0 to 1 . A high value (close to 1.0) indicates that relatively few taxa or species are used by a large proportion of the informants. A low value indicates that the informants disagree on the taxa to be used in the treatment within a category of illness. FIC values are low (near 0) if plants are chosen randomly or if there is no exchange of information about their use among informants; and approach one (1) when there is a well-defined selection criterion in the community and/or if information is exchanged between informants [16]. From the data collected, we could identify ten ailment categories for which the FIC values were computed.

Use value (UV): The relative importance of each plant species known locally to be used as herbal remedy is reported as use value (UV) and it was calculated using the following formula [17].

$$
\mathrm{UV}=\frac{\sum \mathrm{U}}{\mathrm{n}}
$$

Where UV is the use value of a species, $\mathrm{U}$ is the number of use reports cited by each informant for a given plant species and $\mathrm{n}$ is the total number of informants interviewed for a given plant. The UV is helpful in determining the plants with the highest use (most 
frequently indicated) in the treatment of an ailment. Use values are high when there are many use reports for a plant, implying that the plant is important, and approach zero (0) when there are few reports related to its use. The use value, however, does not distinguish whether a plant is used for single or multiple purposes [18].

All the collected data was verified and entered into MS Excel (2007) sheets. SPSS version 17 was used for statistical analyses. Use value and Informant consensus factor formulas was entered in the excel sheet to arrive at the figures for each respondent and the mean $\pm \mathrm{SD}$ computed. The "regular" two-sample t-test was used for comparing the means of different data for two different sample groups (forest area and town area). As we took a random sample through the snow-ball technique of two groups separately and they had different conditions, the samples were independent and we ran an independent samples $t$ test (also called betweensamples and unpaired-samples).

\section{Results}

Kanyakumari district Wild life forest has a variety of medicinal plants that are used by Kani tribes for their primary health care. The plant parts mostly used by the tribals are leaves followed by fruit, seeds, root, bark, whole plant, flowers, stem, rhizome, bulb and gum. These are commonly occurring and medicinally important plants used to treat various diseases like respiratory problems like asthma, skin diseases, hepatitis, diabetic, piles, ulcers, poisonous bites by snakes and insects and wound healing etc,. Most of them still consider traditional herbal knowledge as traditional secrets. But, through repeated contacts, and discussions, they shared their traditional herbal knowledge.

According to the quantitative analysis of survey responses (Table 2), the use value index was different between the two groups of Kaanis. Traditional knowledge regarding medicinal uses of herbs may be tied to cultural practices where useful traditional knowledge is kept secret and mostly passed down the family line for economic reasons and due to spiritual rites. Ocimum Sanctum (Krishna Thulsi) was the plant used the most in both the groups.

Use Value Methods simply counts the number of different uses reported for each plant to assign importance. They require least amount of data collection, less field time and in fact the uses totalled methods could be based only upon literature review. It may be most often applied when documenting knowledge distribution [19]. However, they do not distinguish relative degree of importance for different use. Intra-cultural variability cannot be assessed because data is not recorded per-respondent or informant and these methods ignore the dynamics of cultural importance, such as distinctions between current and historical uses, frequency of use and relative degree of importance.

The decreasing rate of transfer of indigenous knowledge might be due to the lack of interest among the younger generation to learn and practice it, which might be attributed to the ever increasing influence of greater access to the allopathic system of medicine. The use value may depend upon the cultural importance of plant species and researchers have reported differences between different communities and social groups.

\begin{tabular}{|c|c|c|c|}
\hline \multirow{2}{*}{ Name in local language (Tamil) } & \multirow{2}{*}{ Botanical name } & \multicolumn{2}{|c|}{ Use value } \\
\hline & & Kaanis of the forest & Kaanis in the town \\
\hline Vallarai & Centella Asiatica & 0.68 & 0.42 \\
\hline Murivuporunthi & Blepharis Maderaspatens & 0.73 & 0.59 \\
\hline Thuththi & Abutilon Indicum & 0.77 & 0.54 \\
\hline Thumbai & Leucas Aspera & 0.52 & 0.33 \\
\hline Krishna Thulsi & Ocimum Sanctum & 0.89 & 0.81 \\
\hline Nochi & Vitex Negundo & 0.72 & 0.63 \\
\hline Kuppameni & Acalypha Indica & 0.85 & 0.71 \\
\hline Shatavari & Asparagus Racemosus Wild & 0.79 & 0.55 \\
\hline Vilvam & Aegle Marmelos & 0.88 & 0.72 \\
\hline Thazhuthamai & Clerodendrum Phlomides & 0.65 & 0.56 \\
\hline Nayuruvi & Achyranthes Aspera & 0.84 & 0.75 \\
\hline Brahmi & Bacopa Monnieri & 0.48 & 0.32 \\
\hline Uzhinja /Valliuzhinja & Cardiyospermum Halikakabam & 0.55 & 0.42 \\
\hline Adathoda & Adhatoda Vasica Nees & 0.75 & 0.65 \\
\hline Sivanaarvembu & Indigofera Aspalathiodes & 0.42 & 0.32 \\
\hline Ponnavarai & Cassia Auriculata & 0.86 & 0.66 \\
\hline Sirukanpeelai & Aerva Lanata & 0.83 & 0.48 \\
\hline Kurunthotti & Sida Cordifolin & 0.75 & 0.52 \\
\hline Amirthavalli & Tinospora Cordifolia & 0.91 & 0.74 \\
\hline Nilavembu & Andrographis Paniculata & 0.85 & 0.69 \\
\hline
\end{tabular}

Table 2: Evaluation of Ethno medicine by Use Value 
The highest use value of 0.91 was recorded for Tinospora Cordifolia among the forest dwellers, while Achyranthes Aspera had the highest use value among those in the town area. We focused on the use of the leaves of the selected plants. They were mostly used as decoctions, either singly or in combination with some seed spices. When the decoction of dried leaves was used, it was mixed with a little milk before consumption.

The differences in use values between ethnic and gender groups can be explained by the social division of labor in the community. This is consistent with the works of researchers who showed that the difference in use values is not necessarily related to ethnicity. This is illustrated in a study by the fact that the Fulani who were represented in the two study locations did not show similarity in the use values [20]. Therefore, we would also like to conclude that the differences in the use value of the two selected is based other factors and not due to their ethnicity.

\section{Informant consensus factor (FIC)}

To gain credibility, scientific studies that utilize traditional knowledge must be reliable. In Ethno botanical studies, consensus analysis provides a measure of reliability for any given claim providing reliable evidence. The product of FIC ranges from 0 to 1 . A high FIC value indicates the agreement of selection of taxa between informants, whereas a low value indicates disagreement [10]. Commonly FIC of local knowledge for disease treatment depended on the availability of the plant species in the study area [14]. The FIC values in our study ranged from 0.68 to 1 (Table 3 ).

\begin{tabular}{|c|c|c|c|c|c|c|}
\hline \multirow[t]{2}{*}{ Ailment category } & \multicolumn{3}{|c|}{ Kaanis of the forest } & \multicolumn{3}{|c|}{ Kaanis in the town } \\
\hline & $\begin{array}{l}\text { Number of } \\
\text { use reports }\end{array}$ & $\begin{array}{l}\text { Number of } \\
\text { taxa }\end{array}$ & $\begin{array}{c}\text { Informant } \\
\text { consensus } \\
\text { factor }\end{array}$ & $\begin{array}{l}\text { Number of } \\
\text { use reports }\end{array}$ & $\begin{array}{c}\text { Number of } \\
\text { taxa }\end{array}$ & $\begin{array}{c}\text { Informant } \\
\text { consensus } \\
\text { factor }\end{array}$ \\
\hline $\begin{array}{l}\text { Circulatory } \\
\text { system }\end{array}$ & 23 & 3 & 0.91 & 15 & 1 & 1.0 \\
\hline $\begin{array}{l}\text { Respiratory } \\
\text { system }\end{array}$ & 179 & 21 & 0.89 & 155 & 15 & 0.91 \\
\hline Gastro-intesinal & 159 & 25 & 0.85 & 123 & 21 & 0.84 \\
\hline Liver & 110 & 19 & 0.84 & 89 & 13 & 0.86 \\
\hline $\begin{array}{c}\text { Kidney Genito- } \\
\text { urinary }\end{array}$ & 113 & 28 & 0.76 & 52 & 07 & 0.88 \\
\hline Skeleto-muscular & 185 & 27 & 0.86 & 41 & 02 & 0.96 \\
\hline Eye diseases & 32 & 09 & 0.74 & 22 & 01 & 1.0 \\
\hline Ear problems & 46 & 12 & 0.76 & 21 & 01 & 1.0 \\
\hline $\begin{array}{c}\text { Dermatological } \\
\text { problems }\end{array}$ & 134 & 30 & 0.78 & 88 & 14 & 0.85 \\
\hline Poisonous bites & 98 & 32 & 0.68 & 35 & 08 & 0.79 \\
\hline
\end{tabular}

In the present study, eye and ear problems and circulatory system ailments had the highest Fic of 1 among those in the town. The use categories were more among the Kaanis in the forest than in the towns for all ailments reported. In comparison those in the forest had use-reports of circulatory system (23 use reports, 3 species), eye problems (32 use reports 9 species) and dermatological infections /diseases (134 use reports, 30 species). Those in the forest had a greater number of use reports and the number of species of taxa was slightly greater than those in the towns. Therefore we are of the opinion that those in the town area have less access to medicinal plants. Also in the PRA survey we found that those in the town had access to over-the-counter allopathic drugs, which was more convenient to use.

Further, we found that those in the forest area could report more number of taxa for each ailment category when compared to those in the town area. Therefore the consensus factor was slightly lower for each ailment category in the forest dwellers. This is a clear indication of ethno medicinal knowledge fading away as the living environment changes.

Phyllanthus amarus and Coscinium fenestratum were very commonly used for the treatment of Jaundice and Diabetes respectively in these studies. The least agreement between the informants was observed in poisonous bites with a FIC of 0.7 followed by gastrointestinal ailments with a FIC of 0.71 and Dermatological infections /diseases with a FIC of 0.74 . Thus the study indicated that the degree of knowledge shared by the users in the study area regarding the use of medicinal plants in the treatment of ailments was high. Dermatological infections /diseases had the lowest FIC of 0.74 , but this ailment category ranked third in the number of use reports (24) and number of taxa (7) and poisonous bites had the lowest FIC of 0.70, but this ailment category ranked eighth in the number of use reports (11) and number of taxa (4) attributed to this category. It may be due to lack of communication among the informants in the study area who are practicing these ailment categories [21].

We carried out a statistical analysis to compare the use value $(t=0.0011)$ and informant consensus factor $(t=0.0057)$ between the Kaanis of the forest and towns and found that both were significantly different at $\mathrm{p} \leq 0.05$. Hence, we reject the null hypothesis and 
conclude that the knowledge and application of ethno medicinal plants has changed when the Kaani tribes moved out of their original dwelling place, the forest into neighbouring towns.

\section{Discussion}

Ethnic groups of various regions of the world are the real custodians of nature's wealth and experts in herbal medicine. The traditional indigenous knowledge transferred orally for centuries is fast disappearing because of the technological developments and changing culture of ethnic groups [22]. There are 30 different use value methods as comprehended from literature search. The major objectives of such types of studies were the importance of species in a community, degree of decline of use of popular plants, importance of a species for an informant, frequency citation and occurrence of plants, comparison of importance of plant groups, combined studies of cultural, practical and economic values to quantity the average number of informant know how for each species [23].

\section{Conclusion}

The wealth of tribal knowledge of medicinal and other useful plants points to a great potential for research and the discovery of new drugs to fight diseases. The body of existing ethno medical knowledge has led to great developments in health care. With the rapid industrialization of the planet and the loss of ethnic cultures and customs, some of this information will no doubt disappear. An abundance of ethno medical information on plant uses can be found in the scientific literature but has not yet been compiled into a usable form. Collection of ethno medical information especially in the poor countries or developing countries remains primarily an academic endeavour of little interest to most industrial groups.

Plants, herbs, and ethno-botanicals are used since the early days of humankind and are still used throughout the world for health promotion and treatment of disease [24]. This study revealed that medicinal plants still play a vital role in the primary healthcare of the Kaani people. From this account it is clear that the Kaani tribe possess the ability to discern the character of various plants and their beneficial properties. It is interesting to note that such a way of life, particularly with respect to healthcare practices is undergoing changes in the present days due to migration from the forest to town areas. This may be due to the lack of the ethno medicinal plants outside the forest area.

\section{Acknowledgement}

This is part of the research work carried out under the Emeritus Fellowship granted to the first author by UGC, New Delhi, vide Ref.No. No.F.66/ 201617/ EMERITUS2015-17 GEN 8167 /(SAII) dated 01 April 2016.

\section{References}

1. Palanichamy C, Veerabahu R, Mohan, C Kalidas (2010) An Ethno botanical Survey of Medicinal Plants Used By The Kanikkar Tribe of Kanyakumari District of Western Ghats, Tamil Nadu for the Treatment of Skin Diseases. J Herb Med Toxicol 4: 179-90.

2. Tripathi L, Tripathi JN (2003) Role of biotechnology in medicinal plants. Trop J Pharmaceut Res 2: 243-53.

3. WHO (2003) Traditional Medicine. Fact sheet No 134. Geneva, Switzerland.

4. Ayyanar M, Ignacimuthu S (2011) Ethno botanical survey of medicinal plants commonly used by Kani tribals in Tirunelveli hills of Western Ghats, India. J Ethnopharmacol 134: 851-64.

5. Rajakumar N, Shivanna MB (2009) Ethno medicinal application of plants in the eastern region of Shimoga District, Karnataka, India. J Ethnopharmacol 126: 64-73.

6. Ganesan S, Suresh N and Kesavan L (2004) Ethno medicinal Survey of Lower Palani Hills of Tamilnadu, India. IJTK 3: $299-304$.

7. Xavier TF, Kannan M, Lija L, Auxillia A, Rose AK, et al. (2014) Ethno botanical study of Kani tribes in Thoduhills of Kerala, South India. J Ethnopharmacology 152: 78-90.

8. Rajith NP, Ramachandran VS (2010) Ethno medicines of Kurichyas, Kannur District, Western Ghats, Kerala. IJNPR 1: 249-53.

9. ICMR (2006) Ethical Guidelines for Biomedical Research on Human Participants, New Delhi, India.

10. Census of India (2011) Provisional Population Totals, India.

11. Creative research system (2015) Creative research systems, California.

12. Condea BE, De Siqueiraa AM, Rogérioa ITS, Marquesa JS, Borcarda GG, et al. (2014) Synergy in ethno pharmacological data collection methods employed for communities adjacent to urban forest. Braz J Pharmocogn 24: 425-32.

13. Tripathi YC (2007) Ethno-Medico-Botanical Data Sheet.

14. Encyclopedia of medicinal plants (2016) Herbs - Medicinal plants usage and Identification Data base.

15. Heinricha M, Anklib A, Freib B, Weimanna C, Sticherb O (1998) Medicinal plants in Mexico: healers consensus and cultural importance. Soc Sci Med 47: 91-112.

16. Bhatia H, Sharma YP, Manhas RK, Kumar K (2014) Ethno medicinal plants used by the villagers of district Udhampur, J\&K, India. J Ethnopharmacol 151: $1005-18$.

17. Phillips O, Gentry AH, Reynel C, Wilkin P, Galvez-Durand BC (1994) Quantitative ethno botany and Amazonian conservation. Conserv Biol 8: 225-48.

18. Musa MS, Abdelrasool FE, Elsheikh EA, Ahmed LAMN, Mahmud ALE, et al. (2011) Ethno botanical study of medicinal plants in the Blue Nile State, Southeastern Sudan. J Med Plant Res 5: 4287-97.

19. Caldwell KI (2007) Assessing Medicinal Plant Value and Estimating Traditional Environmental Knowledge in Ghana, Africa using Ethno botanical Measures. Graduate Faculty of North Carolina University, USA. 
20. Ragupathy S, Steven NG, Maruthakkutti M, Velusamy B, Ul-Huda MM (2008) Consensus of the 'Malasars' traditional aboriginal knowledge of medicinal plants in the Velliangiri holy hills, India. J Ethnobiol Ethnomed 4: 8.

21. Gouwakinnou GN, Lykke AM, Assogbadjo AE, Sinsin B (2011) Local knowledge, pattern and diversity of use of Sclerocarya birrea. J Ethnobiol Ethnomed 7: 8. 22. Dembélé U, Lykke AM, Koné Y, Témé B, and Kouyaté AM (2015) Use-value and importance of socio-cultural knowledge on Carapa procera trees in the Sudanian zone in Mali. J Ethnobiol Ethnomed 11: 14.

23. Akhtar N, Rashid A, Murad W, Bergmeier E (2013) Diversity and use of ethno medicinal plants in the region of Swat, North Pakistan. J Ethnobiol Ethnomed 9: 25 .

24. Cox AP, Balick JM, (1996) Ethno botanical Research and traditional Health Care in Developing Countries: Plants, People and Culture. WH Freeman and Co New Work, USA.

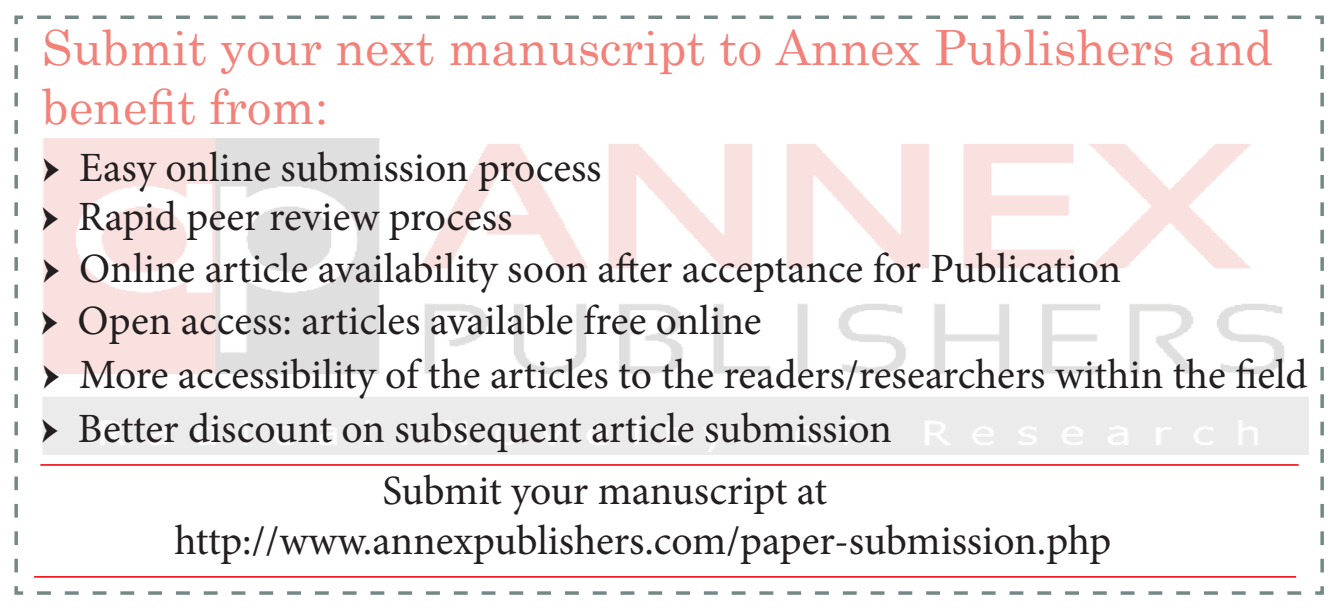

